\title{
Stock Pre-positioning Model with Unsatisfied Relief Demand Constraint to Support Emergency Response
}

\author{
Prudensy Febreine Opit \\ Department of Architecture, Civil Engineering, and Industrial Management Engineering \\ Nagoya Institute of Technology, Nagoya, Japan \\ Email: prudensy_f@yahoo.com (Corresponding Author) \\ Woon-Seek Lee \\ Division of Systems Management and Engineering \\ Pukyong National University, Busan, Korea \\ Email: iewslee@pknu.ac.kr \\ Byung Soo Kim \\ Departement of Industrial and Management Engineering \\ Incheon National University, Incheon, Korea \\ Email: bskim@incheon.ac.kr \\ Koichi Nakade \\ Department of Architecture, Civil Engineering, and Industrial Management Engineering \\ Nagoya Institute of Technology, Nagoya, Japan \\ Email: nakade@nitech.ac.jp
}

\begin{abstract}
Stock prepositioning is one of the most important issues in preparedness stage of emergency logistics response. In a previous research, a stock prepositioning model to support an emergency disaster relief response in the event of earthquake has been proposed. Since the results contained zero proportion of some type of item, which is not allowed in a real system, an improvement of the model is needed. Hence, in this paper we focus on how to prevent the result of zero proportion of a single item type stored in distribution centers, which is the proportion of relief demand satisfied of disaster areas. We propose a new model by adding new variable of proportion of unsatisfied relief demand. Thus, we apply this model to a real case with $\mathbf{3 3}$ disaster areas and 16 distribution centers in Indonesia. Finally, the sensitivity analysis is performed to show the effect of different upper bound of the proportion of unsatisfied relief demand.
\end{abstract}

Keywords : disaster logistics, emergency response, stock prepositioning, proportion of relief demand satisfied, proportion of unsatisfied relief demand

\section{INTRODUCTION}

Disaster management covers large area of disasters classification. Amin and Markus (2008) mention that disasters are classified to natural disasters and technological disasters, or complex emergencies. Disaster Management that covers natural disasters, including earthquake, is required to identify hazard prone and formulate actions that should be prioritized. In the previous year, Whybark (2007) explains the importance of the management of disaster relief inventories. The author also describes the characteristic of disaster relief inventories and shows the significant differences between disaster relief and enterprise inventories. Recently, Galindo and Batta (2013) review that preparedness phase has become one of the most popular studies in disaster operations management (DOM) area. One of the critical studies to perform preparedness phase is pre-positioning theory. Pre-positioning involves preparing critical relief supplies in strategic locations and determining the amount of demand to be released in disaster areas. 
Beamon (2004) explains the concept of stock prepositioning in humanitarian logistics. According to the author, many issues are restrict and need to be focused in pre-positioning stage; including budget limitation, limited number of distribution centers and limited capacity for each distribution center. In addition, the demand is uncertain. Hale and Moberg (2005) also suggest that emergency resources need to be located in a manner as to not be vulnerable to attack. But, they need to be close to the areas to which they are assigned to serve. Afterwards, Balcik and Beamon (2008) develop a model which is a variant of the maximal covering location model. They integrate facility location and inventory decisions. They also consider multiple item types, and capture budgetary constraints and capacity restriction of distribution centers.

Ozbay and Ozguven (2007) concern an efficient and quick-response humanitarian inventory management model which can determine the safety stock that will prevent disruptions at a minimal cost. While almost at the same time, Tovia (2007) builds an emergency response model (ERM) that can be used to evaluate response capabilities, to assess the logistics challenges in the event of natural disaster, specifically hurricane, and to perform what-if analysis on the threat of a weather disturbance system.

Chang et al. (2007) apply the data processing and network analysis functions of the geographic information system to estimate the possible locations of rescue demand points and the required amount of rescue equipment for flood emergency logistics. Three years later, Gatignon et al. (2010) evaluate the decentralized supply chain's performance in responding to humanitarian crises through an analysis of the International Federation of the Red Cross (IFRC)'s operations during the Yogyakarta earthquake in 2006. Just by a year, Lin et.al. (2011) propose a complex logistics model for disaster relief operations. They focus on minimization of total penalty cost of unsatisfied demand, especially for high priority items, and provide a real-world earthquake scenario.

A year earlier, Raftani-Amiri et al. (2010) conduct a multi-period supply network research. They consider multiple food products with time windows on condition that the customer will be served only by one supplier in different time periods. Later, Kähkönen (2011) demonstrates that a proper case study can be conducted in the research field of supply management. The author also emphasizes how the validity and reliability of the case study can be evaluated.

Ozguven and Ozbay (2013) recently develop a humanitarian emergency management framework based on the real-time tracking of emergency supplies and demands through the use of RFID technology integrated. They concern a multi-commodity stochastic humanitarian inventory management model (MC-SHIC) to determine the optimal emergency inventory levels at the minimal cost.
The previous work of Lee, Opit, and Kim (2011) simultaneously determine the decision of distribution centers to cover a single disaster area and the amount of supplies to be stocked in each distribution center. They carefully consider the response time needed for each existing distribution center to serve one or more disaster areas. In their model, the distribution centers have been established by the government and each distribution center is located in a single disaster area. By using their model, the result of the proportion of some type of item is zero due to its higher price or larger size per unit compared to another item. The result was eventually changed (no longer zero) when maximum response time is increased rapidly and each budget is multiplied by ten. But changing the budgets is inappropriate since the budgets were predetermined by the government. In a real system, this result of zero proportion of some critical items could not be tolerated. To support emergency relief response, all critical items should have some amounts to be stocked in distribution centers.

To solve this problem, we propose our new model. In order to obtain the maximum number of inventory stocked, while at the same time preventing the result of zero proportion of a single item type stored in distribution centers, new variable of proportion of unsatisfied relief demand is introduced. First, we use an approach to minimize the lower bound of the proportion of unsatisfied demand of each item under given budgets. After solving the first problem, we generate the upper bound of the proportion of unsatisfied demand. We then maximize the total expected relief demand satisfied by considering the new variable of the proportion of unsatisfied demand. The proposed model is applied to the same real system as in the previous work of Lee et.al (2011), by also maintaining the same data estimation for each parameter. The objective of this paper is to obtain the maximum number of expected relief demand covered by the existing distribution centers by preventing the result of zero proportion of relief demand satisfied under budget constraints.

\section{MODEL FORMULATION}

Each distribution center is located in a single disaster area, and each distribution center can provide service in one or more disaster areas. The same assumption is also used in this model, that the earthquake will not occur at the same time in multiple disaster areas.

\section{Data set:}

$i=$ disaster area; $j=$ distribution center;

$J^{i}=$ distribution center $j$ that provide service in disaster area $i$;

$k=$ item type. 


\section{Parameters:}

$T_{i j} \quad$ expected time to satisfy relief demand in disaster area $i$ from distribution center $j$ (hour),

$\delta_{i} \quad$ maximum response time limit to perform emergency response in disaster area $i$ (hour),

$u_{k} \quad$ upper bound of the proportion of unsatisfied relief demand of item type $k\left(u_{k}=Z_{k}+\left(1-Z_{k}\right) * m_{k}\right)$, where $Z_{k}<u_{k}<1$ and $0<m_{k}<1$,

$m_{k}$ degree of importance of item type $\mathrm{k}$; where $m_{k}=$ $m, \forall k$,

$P_{i} \quad$ probability of occurrence of earthquake in disaster area $i$,

$d_{i k} \quad$ expected demand for item type $k$ in disaster area $i$ (unit),

$U_{j} \quad$ capacity of distribution center $j\left(\mathrm{~m}^{3}\right)$,

$\gamma_{k} \quad$ unit volume of item type $k\left(\mathrm{~m}^{3}\right)$,

$B_{0} \quad$ pre-disaster budget (\$),

$B_{1}$ post-disaster budget (\$),

$g_{j k}$ unit cost of acquiring item type $k$ at distribution center $j$ (\$/unit),

$c_{i j k}$ unit cost of shipping item type $k$ from distribution center $j$ to demand point $i$ (\$/unit),

$w_{k}$ criticality weight for item type $k ; \sum_{k} w_{k}=$ 1 and $w_{k} \geq 0$

$M \quad$ a very large positive number.

\section{Decision variables:}

$f_{i j k}$ proportion of item type $k$ relief demand satisfied by distribution center $j$ that provide services in disaster area $i$,

$N_{i k}$ proportion of unsatisfied relief demand of item type $k$ in disaster area $i$,

$Z_{k}$ the lower bound of the proportion of unsatisfied relief demand of item type $k$,

$Q_{j k} \quad$ units of item type $k$ stored at distribution center $j$,

$a_{i j} \quad$ set of potential response time of distribution center $j$ that will provide service in disaster area $i\left(a_{i j}=1\right.$; if expected time $T$ is no bigger than maximum response time limit, 0 otherwise),

$X_{i j}$ set of potential distribution center $j$ to provide service in disaster area $i\left(X_{i j}=1\right.$, if distribution center $j$ provides service in disaster area $i, 0$ otherwise).

\subsection{Generating Lower Bound of the Proportion of Unsatisfied Demand}

The problem consists of two models. In the first model, we derive the following problem (1-k) for each item type $\mathrm{k}$ in $\{1,2, \ldots, \mathrm{k}\}$.

\section{Objective function}

$$
\operatorname{Min}=Z_{k} \text {. }
$$

\section{Constraints:}

$$
\begin{array}{ll}
\sum_{k \in K} f_{i j k} \leq M X_{i j}, & \forall i \epsilon I, j \epsilon J, \\
\sum_{j \epsilon J} f_{i j k}=1-N_{i k}, & \forall i \epsilon I, k \epsilon K, \\
N_{i k} \leq Z_{k} & \forall i \epsilon I, \\
f_{i j k} d_{i k} \leq Q_{j k}, & \forall i \epsilon I, j \epsilon J, k \epsilon K, \\
\sum_{k \in K} \gamma_{k} Q_{j k} \leq U_{j}, & \forall j \epsilon J, \\
\sum_{j \in J} \sum_{k \epsilon K} Q_{j k} g_{j k} \leq B_{o}, & \\
\sum_{k \epsilon K} \sum_{j \epsilon J} d_{i k} c_{i j k} f_{i j k} \leq B_{1}, & \forall i \epsilon I, \\
f_{i j k} \geq 0, & \forall i \epsilon I, j \epsilon J, k \epsilon K, \\
N_{i k} \geq 0, & \forall i \epsilon I, k \epsilon K, \\
a_{i j} T_{i j} \leq \delta_{i}, & \forall i \epsilon I, j \epsilon J, \\
a_{i j} \geq X_{i j}, & \forall i \epsilon I, j \epsilon J, \\
\sum_{j \in J} X_{i j} \geq 1, & \forall i \epsilon I, i \neq j, \\
a_{i j} \in(0,1), & \forall i \epsilon I, j \epsilon J, \\
X_{i j} \in(0,1), & \forall i \epsilon I, j \epsilon J .
\end{array}
$$

The objective function (1) minimizes lower bound of the proportion of unsatisfied relief demand of each item type. Constraint set (2) ensures the amount of supplies sent to satisfy relief demand that only exists when the distribution center provides service in designated disaster areas. Constraint set (3) means that the actual demand is equal to the amount of satisfied relief demand summed with the amount of unsatisfied relief demand in a specific disaster area. Constraint set (4) assures that the proportion of unsatisfied relief demand does not exceed the desired lower bound limit. Constrain set (5) requires the inventory level at a single distribution center that is no smaller than the maximum amount of demand. Constraint set (6) guarantees that the amount of inventory kept at any distribution center does not exceed its capacity. Constraint set (7) requires that the preparedness expenditures related to provision of logistics for basic needs in emergency does not exceed the pre-disaster budget. Constraint set (8) means that the transportation costs to mobilize resources are less than the expected post-disaster budget. Constraint set (9) describes the non-negativity constraint on the proportion of demand satisfied. Constraint set (10) describes the non-negativity constraint on the proportion of unsatisfied demand. Constraint set (11) guarantees that the existing distribution center can only provide service in specific disaster area if the expected time to satisfy relief demand is no bigger than the maximum response time limit. Constraint set (12) guarantees that a distribution center will not provide service in specific disaster area if the expected time to satisfy relief demand is bigger than the maximum response time limit. Constraint set (13) assures that at least one distribution center will provide service in any disaster area. Constraint set (14) and (15) 
define the binary variable of potential response time and service area for each distribution center, respectively.

\subsection{Maximizing the Total Expected Relief Demand Satisfied of Disaster Areas}

Next, in the second model, the objective function (16) is now maximizing the total expected relief demand covered by the existing distribution centers, while constraint set (4) is needed to be modified. Since the value of optimal lower bound of the proportion of unsatisfied relief demand has been generated in the first model, we should be able to determine the value of the upper bound of the proportion of unsatisfied relief demand, where $u_{k}=Z_{k}+\left(1-Z_{k}\right) * m_{k}$ and $Z_{k}<u_{k}<$ 1. The new constraint set (17) guarantees that the proportion of unsatisfied relief demand in each disaster area is smaller than the desired upper bound limit. In spite of these two changes, other constraints are remaining the same (refer to section 2.1).

\section{Objective function:}

$$
\operatorname{Max}=\sum_{i \in I} \sum_{k \in K} \sum_{j \in J^{i}} p_{i} d_{i k} w_{k} f_{i j k} .
$$

\section{Modified constraint:}

$$
N_{i k} \leq u_{k}, \quad \forall i \epsilon I, k \in K
$$

It is necessary to provide an adjustment to the model to be used in the real system. The constraint set (13) is changed to:

$$
\begin{array}{ll}
\sum_{j \in J} X_{i j} \geq 2, & \forall i \in I_{1}, \\
\sum_{j \in J} X_{i j} \geq 1, & \forall i \in I_{0} .
\end{array}
$$

Constraint set (18) assures that at least two distribution centers will provide services in disaster area that already has one existing distribution center $\left(I_{1}\right)$. While constraint set (19) assures that at least one distribution center will provide service in disaster area with zero existing distribution center $\left(I_{0}\right)$.

\section{DATA CONSTRUCTION}

To show the improvement of the results of our new model, we ran the model under the same data as in previous paper. Indonesia, a developing country that is located in South-East Asia and considered as an earthquake-prone country, remains our main focus. Table 1 shows the number of disaster areas, distribution centers, and item types.

Number of disaster areas is 33 based on 33 provinces existed in Indonesia in year 2011. Number of distribution centers is 16 . They are located in 16 different disaster areas. In this case, a distribution center serves one or more disaster areas and one disaster area possibly served by one or more distribution centers. Commonly, disaster relief consists of many items. The items needed are very diverse and difficult to be accurately satisfied. In this paper, the items are limited up to nine critical item types. These nine items are the most priority items and need to be available in each distribution center.

Table 2 depicts the data estimation. Related to the calculation of expected response time, helicopters are used to transport each item to the affected area. The expected loading time is set to be 2 hours (the same for each item). The maximum response time limit is set to be 8 hours, while in the reality this number is flexible, depends on the government policy.

The probability of earthquake for each disaster area is estimated by the team of Indonesia's earthquakes map revision (2010) using the principal of 6 earthquake zones of Indonesia. Indonesia population in year 2010 is used for the demand estimation while criticality weights are obtained by classifying all items into two groups: primary and secondary items. The capacity of each distribution center is obtained by assuming the dimension of each distribution center is $100 * 100 * 12=120,000 \mathrm{~m}^{3}$. Normally, only $70 \%$ space is used for the storage. Hence, the capacity of each distribution center is $84,000 \mathrm{~m}^{3}$.

Unit cost of acquiring relief item is estimated from the purchase price of each item. To calculate the unit cost of shipping, it is necessary to assume the maximum load of helicopter. The maximum load of medium size of helicopter can be assumed to be $6.23 \mathrm{~m}^{3}$ for one way trip. It is also important to be noticed that pre-disaster and post-disaster budgets were predetermined by the government. In this paper, maximum pre-disaster and post-disaster budgets were adapted from the budget allocation of Indonesian government in period 2010-2014. (National Agency for Disaster Management of Indonesia, 2009).

\section{COMPUTATIONAL RESULTS}

LINGO 8.0 was used for finding the optimal solutions with the mathematical model presented in section 2 (Model Formulation). All experiments solving each problem are tested on a personal computer with an Intel (R) Core (TM) 2 Duo CPU $2.93 \mathrm{GHz}$ and $2.00 \mathrm{~GB}$ of RAM. The computation time of all the test problems was less than 1 minute.

At first, we ran the model which minimized lower bound of the proportion of unsatisfied relief demand of each item type. This model ran under pre-disaster budget of USD 857,317,919.08; post-disaster budget of USD 116,589,595.38; maximum response time of 8 hours; and capacity of each distribution center of $84,000 \mathrm{~m}^{3}$. The results are (for item type A to I): $0.949 ; 0.000 ; 0.277$; $0.000 ; 0.000 ; 0.791 ; 0.851 ; 0.000 ; 0.000$. Then we continued to the next model formulation. 
Table 1. Data set

\begin{tabular}{|c|c|c|c|c|}
\hline \multirow{10}{*}{$\begin{array}{l}\text { Number of } \\
\text { disaster area:33 }\end{array}$} & 1. Aceh* & 9. South Sumatra* & 17. Bali & 25. South Sulawesi* ${ }^{*}$ \\
\hline & 2. North Sumatra* & 10. Lampung* & 18. West Nusa Tenggara* & 26. South East Sulawesi \\
\hline & 3. $\operatorname{Riau}^{*}$ & 11. Banten* & 19. East Nusa Tenggara* & 27. Central Sulawesi* \\
\hline & 4. West Sumatra & 12. Jakarta & 20. West Kalimantan & 28. Gorontalo* \\
\hline & 5. Jambi & 13. West Java & 21. Central Kalimantan* & 29. North Sulawesi \\
\hline & 6. Riau Island & 14. Central Java & 22. South Kalimantan & 30. North Maluku \\
\hline & 7. Bangka-Belitung & 15. Yogyakarta* & 23. East Kalimantan* & 31. Maluku* \\
\hline & 8. Bengkulu & 16. East Java* & 24. West Sulawesi & 32. West Papua \\
\hline & & & & 33. Papua \\
\hline & \multicolumn{4}{|c|}{ *) Disaster area with one existing distribution center } \\
\hline \multirow{4}{*}{$\begin{array}{l}\text { Number of } \\
\text { distribution } \\
\text { center:16 }\end{array}$} & 1. Banda Aceh & 5. Bandar Lampung & 9. Mataram & 13. Samarinda \\
\hline & 2. Medan & 6. Serang & 10. Makassar & 14. Palu \\
\hline & 3. Tanjung Pinang & 7. Yogyakarta & 11. Kupang & 15. Gorontalo \\
\hline & 4. Palembang & 8. Surabaya & 12. Palangkaraya & 16. Ambon \\
\hline \multirow{4}{*}{$\begin{array}{l}\text { Number of item } \\
\text { type:9 }\end{array}$} & A. Medicine (box) & D. Drinking water & G. Tent (unit) & \\
\hline & B. Instant food (box) & (box) & H. Mat (unit) & \\
\hline & C. Rice(per $50 \mathrm{Kg}$ sack) & E. Blanket (unit) & I. Lantern lamp (unit) & \\
\hline & & F. Clothes (packet) & & \\
\hline
\end{tabular}

Table 2. Data estimation

\begin{tabular}{|c|c|}
\hline Expected response time & $\begin{array}{l}\text { (distance from distribution center to the affected area }(\mathrm{Km})) \text { / vehicle speed }(\mathrm{Km} / \mathrm{hr}))+ \\
\text { (expected loading time }(\mathrm{hr}))\end{array}$ \\
\hline Maximum response time & Expected to be 8 hours since the earthquake (the same for each disaster area) \\
\hline Probability of earthquake & $\begin{array}{l}\text { Calculated based on the frequency of earthquake hit each disaster area during 2005-2010. } \\
\text { The earthquake magnitude varies between } 1.0 \text { to } 9.0 \mathrm{Mw} \text {. }\end{array}$ \\
\hline Amount of demand & Estimated from the total population of each province in 2010. \\
\hline Criticality weight & $\begin{array}{l}\text { Weight of each item type / total weight (Weight of item type A to I respectively }=0.13,0.13 \text {, } \\
0.13,0.13,0.07,0.13,0.13,0.07,0.07)\end{array}$ \\
\hline Volume & $\begin{array}{l}\text { Unit volume of item type A to I respectively }=0.01887 \mathrm{~m}^{3} 0.054 \mathrm{~m}^{3} 0.02 \mathrm{~m}^{3} 0.054 \mathrm{~m}^{3} 0.009 \mathrm{~m}^{3} \\
0.1119 \mathrm{~m}^{3} 0.2 \mathrm{~m}^{3} 0.05625 \mathrm{~m}^{3} 0.005625 \mathrm{~m}^{3}\end{array}$ \\
\hline Distribution center capacity & $84,000 \mathrm{~m}^{3}$ (the same for each distribution center) \\
\hline Unit cost of acquiring relief items & $\begin{array}{l}\text { Unit cost of item type A to I respectively }=\$ 364.162 ; \$ 5.78 ; \$ 0.925 \$ 3.699 ; \$ 6.936 ; \$ 11.561 \text {; } \\
\$ 751.445 ; \$ 8.671 ; \$ 8.092 \text {. (1 USD = Rp. 8,650) }\end{array}$ \\
\hline \multicolumn{2}{|l|}{$\begin{array}{l}\text { Unit cost of shipping from distribution center } \\
\text { to the affected area }\end{array}$} \\
\hline Maximum pre-disaster budget available & $\$ 857,317,919.075$ \\
\hline Maximum post-disaster budget available & $\$ 116,589,595.375$ \\
\hline
\end{tabular}

As we explained in the previous section, this paper focuses on how the new variable of the proportion of unsatisfied relief demand will improve the final result of preventing the zero proportion of a single item type stored in distribution centers. Hence, scenario for sensitivity analysis by changing the upper bound of the proportion of unsatisfied relief demand under given budgets is performed. The upper bound of each item type depends on government policy, which is assumed to vary from 0.780 to 0.999 (Table 3).

For further noticed, the results of grouping service area for each distribution center were not discussed in this paper, especially because the new results indicated no differences from the previous results. This problem was fully discussed in the previous paper (Lee et al., 2011). Furthermore, by changing the upper bound of the 
proportion of unsatisfied demand, we get the new results of the average proportion of satisfied relief demand (Table 4).

We can see from Table 4 that there are no zero results or zero proportions of satisfied relief demand for each item type. This means, all item types are stored in distribution centers, including item type G, although it has larger volume and higher price. This new result is quite different from the previous work, where the amount of item type $\mathrm{G}$ stocked in distribution centers is zero (no stock). By applying this new model, the limitation can be eliminated.

Another difference between the new and previous result can be seen from the number of total inventory, which in this case is a total expected relief demand satisfied in disaster areas. The previous model generated a total of 17,979,240 expected relief demand satisfied, while in the new model the number varies between
$16,703,300$ to $17,955,520$. The number is smaller compared to the number generated by the previous model, but this smaller number covered each item type stored in distribution centers. This means the new model can be applied to the real systems.

Due to budget limitations, the average proportion of each item type could not even reach 1.00. To increase the total proportion of satisfied relief demand, or to decrease the total proportion of unsatisfied relief demand, the government needs to upgrade their budgets (for some countries, this plan is very difficult to be realized). In spite of this limitation, we consider scenario 1 as the best scenario because most of its critical items have lower proportion of unsatisfied relief demand compared to other scenarios. Also, we noticed that the bigger the upper bound of the proportion of unsatisfied relief demand inputted, the bigger the amount of expected relief demand satisfied in disaster areas resulted.

Table 3. Scenario for sensitivity analysis

\begin{tabular}{ccc}
\hline Scenario & $\begin{array}{c}\text { Degree of Importance of } \\
\text { All Item Types }\end{array}$ & $\begin{array}{c}\text { Upper Bound of the Proportion of Unsatisfied Relief Demand of Item Type } \\
\text { A to I }\end{array}$ \\
\hline $\mathbf{1}$ & 0.78 & $0.989 ; 0.780 ; 0.841 ; 0.780 ; 0.780 ; 0.954 ; 0.967 ; 0.780 ; 0.780$ \\
\hline $\mathbf{2}$ & 0.80 & $0.989 ; 0.800 ; 0.855 ; 0.800 ; 0.800 ; 0.958 ; 0.970 ; 0.800 ; 0.800$ \\
\hline $\mathbf{3}$ & 0.85 & $0.992 ; 0.850 ; 0.892 ; 0.850 ; 0.850 ; 0.969 ; 0.978 ; 0.850 ; 0.850$ \\
\hline $\mathbf{4}$ & 0.90 & $0.995 ; 0.900 ; 0.928 ; 0.900 ; 0.900 ; 0.979 ; 0.985 ; 0.900 ; 0.900$ \\
\hline $\mathbf{5}$ & 0.99 & $0.999 ; 0.990 ; 0.993 ; 0.990 ; 0.990 ; 0.998 ; 0.999 ; 0.990 ; 0.990$ \\
\hline
\end{tabular}

Table 4. Average proportion of satisfied and unsatisfied relief demand for each item type

\begin{tabular}{|c|c|c|c|c|c|c|c|c|c|c|c|}
\hline & \multirow[b]{2}{*}{ Scenario } & \multirow{2}{*}{$\begin{array}{l}\text { Total } \\
\text { Expected } \\
\text { Relief } \\
\text { Demand }\end{array}$} & \multicolumn{9}{|c|}{ Item Type } \\
\hline & & & $\begin{array}{c}(\mathrm{A}) \\
\text { Medicine }\end{array}$ & $\begin{array}{c}(\mathrm{B}) \\
\text { Instant } \\
\text { food }\end{array}$ & $\begin{array}{c}(\mathrm{C}) \\
\text { Rice }\end{array}$ & $\begin{array}{c}\text { (D) } \\
\text { Drinking } \\
\text { water }\end{array}$ & $\begin{array}{c}(\mathrm{E}) \\
\text { Blanket }\end{array}$ & $\begin{array}{c}(\mathrm{F}) \\
\text { Clothes }\end{array}$ & $\begin{array}{c}(\mathrm{G}) \\
\text { Tent }\end{array}$ & $\begin{array}{l}(\mathrm{H}) \\
\text { Mat }\end{array}$ & $\begin{array}{c}(\mathrm{I}) \\
\text { Lantern } \\
\text { Lamp }\end{array}$ \\
\hline \multirow{5}{*}{$\begin{array}{l}\text { Average } \\
\text { Proportion } \\
\text { of Satisfied } \\
\text { Relief } \\
\text { Demand }\end{array}$} & 1 & $16,703,300$ & 0.353 & 0.865 & 0.876 & 0.865 & 0.911 & 0.595 & 0.318 & 0.821 & 0.938 \\
\hline & 2 & $17,053,820$ & 0.362 & 0.850 & 0.893 & 0.848 & 0.919 & 0.589 & 0.296 & 0.810 & 0.938 \\
\hline & 3 & $17,532,810$ & 0.377 & 0.832 & 0.906 & 0.833 & 0.934 & 0.576 & 0.232 & 0.793 & 0.954 \\
\hline & 4 & $17,707,590$ & 0.396 & 0.813 & 0.911 & 0.824 & 0.934 & 0.591 & 0.159 & 0.734 & 0.988 \\
\hline & 5 & $17,955,520$ & 0.438 & 0.798 & 0.919 & 0.801 & 0.934 & 0.591 & 0.016 & 0.677 & 0.988 \\
\hline \multirow{5}{*}{$\begin{array}{l}\text { Average } \\
\text { Proportion } \\
\text { of } \\
\text { Unsatisfied } \\
\text { Relief } \\
\text { Demand }\end{array}$} & 1 & $16,703,300$ & 0.647 & 0.135 & 0.124 & 0.135 & 0.089 & 0.405 & 0.682 & 0.179 & 0.062 \\
\hline & 2 & $17,053,820$ & 0.638 & 0.150 & 0.107 & 0.152 & 0.081 & 0.411 & 0.704 & 0.190 & 0.062 \\
\hline & 3 & $17,532,810$ & 0.623 & 0.168 & 0.094 & 0.167 & 0.066 & 0.424 & 0.768 & 0.207 & 0.046 \\
\hline & 4 & $17,707,590$ & 0.604 & 0.187 & 0.089 & 0.176 & 0.066 & 0.409 & 0.841 & 0.266 & 0.012 \\
\hline & 5 & $17,955,520$ & 0.562 & 0.202 & 0.081 & 0.199 & 0.066 & 0.409 & 0.984 & 0.323 & 0.012 \\
\hline
\end{tabular}

\section{CONCLUSION AND FUTURE RESEARCH}

In this paper, we propose a new model of emergency deployment that focuses on preventing the result of zero proportion of a single item type stored in distribution centers. The proposed model is applied to a real case with 33 disaster areas and 16 distribution centers in Indonesia. The results of the new model showed a significant improvement compared to the results generated by the previous model. By adding new variable of proportion of unsatisfied relief demand, the 
amount of each item type stocked in distribution centers is no longer zero. This result is acceptable, based on government policy that requires the availability of each critical item type in distribution centers.

This paper leads to several directions for future research. We found that it is very interesting to coordinate the transportation of commodities from distribution centers to disaster area and enable the selection of the best locations of distribution centers to dispatch the demand in disaster area. This research will become more complex because it integrates the three major problems of logistics coordination: facility location, stock pre-positioning, and transportation planning. This future research will result in higher accuracy and more output compared to solve the problem individually.

\section{REFERENCES}

Amin, S., and Markus, G. (2008). Data Against Natural Disasters, Establishing Effective Systems for Relief, Recovery, and Reconstruction [Online]. Available in: https://openknowledge.worldbank.org/handle/10986/6511

Balcik, B., and Beamon, B.M. (2008).Facility Location in Humanitarian Relief International Journal of Logistics: Research and Applications, 11 (2), pp. 101-121.

Beamon, B. M. (2004). Humanitarian Relief Chains: Issues and Challenges.The $34^{\text {th }}$ International Conference on Computers and Industrial Engineering, San Fransisco pp. 77-82.

Chang, M.S., Tseng, Y.L., and Chen, J.W. (2007). A Scenario Planning Approach for the Flood Emergency Logistics Preparation Problem Under Uncertainty Transportation Research Part E, 43 (6), pp. 737-754.

Galindo, G., and Batta, R. (2013). Review of Recent Developments in OR/MS Research in Disaster Operations Management. European Journal of Operational Research 230 (2), pp. 201-211.

Gatignon, A., Van Wassenhove, L., and Charles, A. (2010).The Yogyakarta Earthquake: Humanitarian Relief through IFRC's Decentralized Supply Chain. International Journal of Production Economics 126 (1), pp. 102-110.

Hale, T., and Moberg, C.R. (2005). Improving Supply Chain Disaster Preparedness, A Decision Process for Secure Site
Location. International Journal of Physical Distribution and Logistics Management 35 (3), pp.195-207.

Kähkönen, A. (2011). Conducting a Case Study in Supply Management. Operations and Supply Chain Management 4 (1), pp. 31-41.

Lee, W.S., Opit, P. F., and Kim, B. S. (2011). A Stock Prepositioning Model to maximize the Total Expected Relief Demand of Disaster Areas. 2011 Fall Conference of Korean Institute of Industrial Engineers, Seoul. pp. 11211128.

Lin, Y. H., Batta, R., Rogerson, P. A., Blatt, A., Flanigan, M., and Lee, K. (2011).A Logistics Model for Emergency Supply of Critical Items in the Aftermath of a Disaster. Socio-Economic Planning Sciences 45 (4), pp. 132-145.

National Agency for Disaster Management of Indonesia. (2009). National Disaster Management Plan 2010-2014 [Online]. Available in: http://www.bnpb.go.id/website/asp/pub.asp?p=4

Ozbay, K., and Ozguven, E. E.(2007). Stochastic Humanitarian Inventory Control Model for Disaster Planning. Transportation Research Record: Journal of the Transportation Research Board 2022 (1), pp. 63-75.

Ozguven, E. E., and Ozbay, K. (2013). A secure and efficient inventory management system for disasters, Transportation Research Part C 29, pp. 171-196.

Raftani-Amiri, Z., Fazlollahtabar, H., and Mahdavi-Amiri, N. (2010). A multi-period Supply Network of Food Products Based on Time-Windows with Sensitivity Analysis. Operations and Supply Chain Management 3 (2), pp. 105116.

Team of Indonesia's Earthquakes Map Revision.(2010). Summary of the Study Result of the Team of Indonesia's Earthquakes MapRevision [Online].Available in:http://mpbi.org/content/ringkasan-hasil-studi-tim-revisipeta-gempa-indonesia-2010

Tovia, F. (2007).An Emergency Logistics Response System for Natural Disasters. International Journal of Logistics: Research and Applications 10 (3), pp. 173-186

Whybark, D. C. (2007).Issues in managing disaster relief inventories. International Journal of Production Economics 108 (1), pp. 228-235.

Pudensy Febreine Opit is currently a first-year Ph.D student in the Department of Architecture, Civil Engineering and Industrial Management Engineering at Nagoya Institute of Technology, Japan. She is listed as a lecturer in the Department of Industrial Engineering, De La Salle Catholic University of Manado, Indonesia. She received her M.Eng from Division of Systems Management and Engineering, Pukyong National University, Republic of Korea. Her Ph.D research focuses on the area of Applied Operations Research in Disaster Logistics and Supply Chain Management.

Dr. Woon-Seek Lee is a Professor of Division of Systems Management \& Engineering and a vice president of planning at Pukyong National University, Republic of Korea. He received his M.S. and Ph.D. from Industrial Engineering Department at Korea Advanced Institute of Science \& Technology (KAIST). His research interests are in the area of Applied O.R. in Production and Logistics Systems, Supply Chain Management, and Management of Technology. He is a member of KIIE, KORMS, KMES, KSS, KSBV, and KOPOMS. 
Dr. Byung Soo Kim is an assistant professor of Department of Industrial and Management Engineering at Incheon National University, Republic of Korea. He received his M.S. and Ph.D from Department of Industrial and Systems Engineering at Auburn University, AL, U.S. His research interests are in the area of Applied O.R. in Supply Chain Management, 3PL Logistics Planning, Warehouse Control, Production Management and Scheduling. He is a member of KIIE, KORMS, and KSCM.

Dr. Koichi Nakade is a Professor in the Department of Architecture, Civil Engineering and Industrial Management Engineering at Nagoya Institute of Technology, Japan. He received a Ph.D from Nagoya Institute of Technology. His research interest covers the Analysis of Stochastic Models as Queues, Markov Processes, Game Theory, and Inventory Models and their Applications to Production Systems and Supply Chains. 